\title{
COMMUNICATIONS
}

\section{THE EFFECT OF CERVICAL SYMPATHOTOMY ON AN OCULAR RESPONSE TO HYPOTHALAMIC STIMULATION*}

\author{
BY
}

\author{
J. GLOSTER AND D. P. GREAVES \\ Institute of Ophthalmology, University of London \\ Director of Research, Sir Stewart Duke-Elder
}

RECENT work (von Sallmann and Lowenstein, 1955; Gloster and Greaves, 1956,1957 ) has shown that in the cat electrical stimulation of the diencephalon is accompanied by changes in intra-ocular pressure. Many of these effects can be attributed to simultaneous changes in the systemic blood pressure, but in a previous study we demonstrated that a reduction in intra-ocular pressure could occur with a rise in blood pressure and was accompanied by bilateral pupillary dilatation with occasional retraction of the nictitating membrane. This type of response was obtained from a limited area in the medial hypothalamus near the anterior column of the fornix (Gloster and Greaves, 1956, 1957). We suggested that this response of the intra-ocular pressure was due to a reduction of capillary blood pressure within the eye. However, the accompanying rise in systemic blood pressure, which probably results from a general sympathetic discharge, would ordinarily cause a rise in capillary blood pressure, and it is therefore necessary to postulate that this tendency is outweighed by a constriction of the ocular blood supply, which is possibly due to local sympathetic activity. This hypothesis can be tested by examining the effect of cervical sympathotomy on the response.

It is the purpose of this paper to describe the response in greater detail and to show that the results of cervical sympathotomy do, in fact, support our hypothesis.

\section{Methods}

The experimental procedure followed in this study was essentially the same as that described fully in a previous paper (Gloster and Greaves, 1957). Cats were anaesthetized by intravenous injections of chloralose $(100 \mathrm{mg} . / \mathrm{kg}$.$) , the femoral$ blood pressure, intra-ocular pressures, and nictitating membrane responses being recorded continuously on a photographic film (Greaves and Perkins, 1952). In five animals a portion of the preganglionic cervical sympathetic nerve was exposed on each side of the neck and carefully separated from the vagus for about $5 \mathrm{~mm}$., a thin silk thread being passed round the nerve to allow identification when required. After the head of the animal had been mounted in the stereotaxic apparatus, the stimulating electrode was placed in a suitable position in the medial part of the hypothalamus and moved downwards in steps of $1 \mathrm{~mm}$. until the 
characteristic response was obtained on stimulation. After the response had been recorded, preganglionic cervical sympathotomy was performed on the side of stimulation. Stimulation was then repeated without changing the position of the electrode. In three animals the cervical sympathetic nerve was then cut on the side opposite to that of stimulation and the response to a further stimulation was recorded. In one animal the blood vessels of the ear on the side of stimulation were observed through a microscope before, during, and after the application of each stimulus.

At the conclusion of the experiment the brain was removed and sectioned in order to determine the position of the tip of the electrode.

\section{Results}

\section{(A) Characteristics of the Response}

In its most easily recognizable form the response consists of:

(1) A fall in intra-ocular pressure in the ipsilateral* eye.

(2) A rise in systemic blood pressure.

(3) Retraction of the nictitating membrane.

(4) Pupillary dilatation.

The constant feature of the response is the fall in intra-ocular pressure occurring in the ipsilateral eye, the other components showing some variation. The following account is derived from experiments on fourteen animals.

The fall in intra-ocular pressure in the ipsilateral eye generally amounted to 1 to $3 \mathrm{~cm}$. saline, although a fall of $6 \mathrm{~cm}$. was noted on one occasion. Fig. $1 a$ (opposite) is a tracing showing the main features of the response. Sometimes a small temporary elevation of intra-ocular pressure was found at the beginning of stimulation, with a similar depression at the end (see Fig. 4, below). The fall in intra-ocular pressure usually lasted throughout the period of stimulation but was occasionally transient. In ten of the fourteen animals the intra-ocular pressure also fell in the contralateral eye but not usually to the same extent as in the ipsilateral eye.

A rise of 5 to $65 \mathrm{~mm}$. $\mathrm{Hg}$ in blood pressure accompanied the fall in intraocular pressure in eleven out of fourteen animals. In one animal the blood pressure fell (Fig. $1 b$ opposite), and the other two showed complex responses in which a slight fall in blood pressure was preceded by a short but definite rise.

Retractions of the ipsilateral nictitating membrane occurred in eight animals, and in three of these the effect was bilateral, although the response of the contralateral membrane was weaker.

Pupillary dilatation occurred in all but one animal. In eight animals the dilatation was equal on the two sides, but it was greater in the ipsilateral eye in the remaining five. The dilatation was brisk, commencing usually within

* The word "ipsilateral"' is used throughout this paper as denoting the same side as that of hypothalamic stimulation; "contralateral" always refers to the side opposite to that of stimulation. 
CAT 31

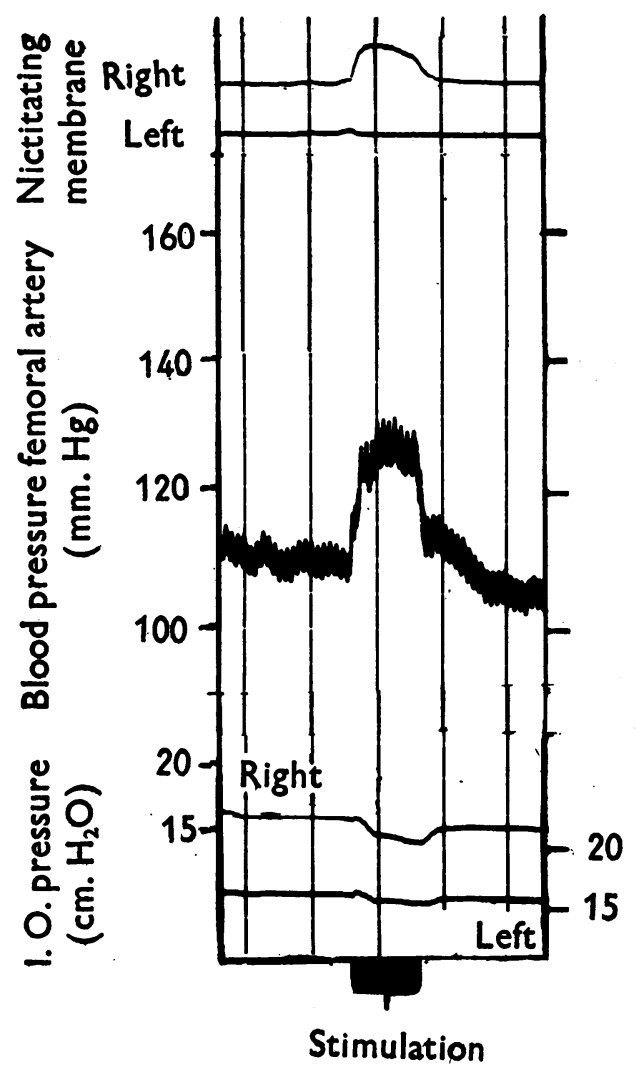

CAT 67

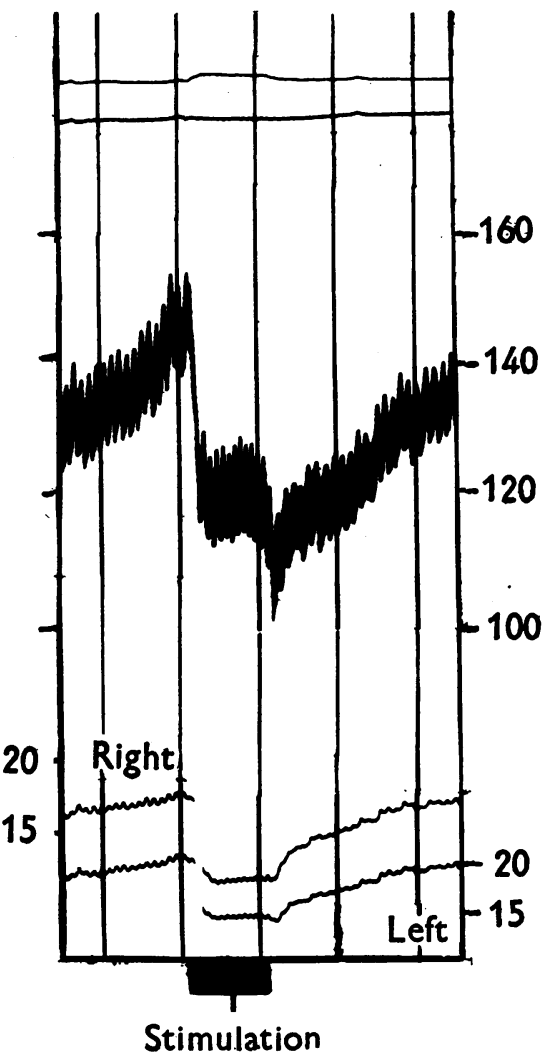

FIG. 1 (b).-Tracing showing large bilateral fall in intra-ocular pressure with accompanying fall in blood pressure. Note also retraction of right nictitating membrane.

Fig. 1 (a).-Tracing showing fall in intraocular pressure with a simultaneous rise in blood pressure. Note also retraction of right nictitating membrane.

Interval between vertical lines $=60 \mathrm{sec}$. Localization: $A 10, R 1 \cdot 5, \mathrm{H}+5 \frac{1}{2}$.

1 second of the onset of stimulation, reaching a maximum in about 5 to 10 seconds, and lessening after 40 to 45 seconds. The amount of dilatation was usually 6 to $8 \mathrm{~mm}$., reaching 9 to $10 \mathrm{~mm}$. in three animals.

\section{(B) Localization of Effective Stimuli}

This response has been obtained from the stimulation of points situated mainly in the medial hypothalamus in frontal planes 10 to $13 \mathrm{~mm}$. anterior to the inter-aural line (A10 to A13). It appeared that the response was most frequently obtained from points in A12 and their distribution is shown in Fig. 2 (overleaf); a section of the brain in one of these experiments is illustrated in Fig. 3 (overleaf). 


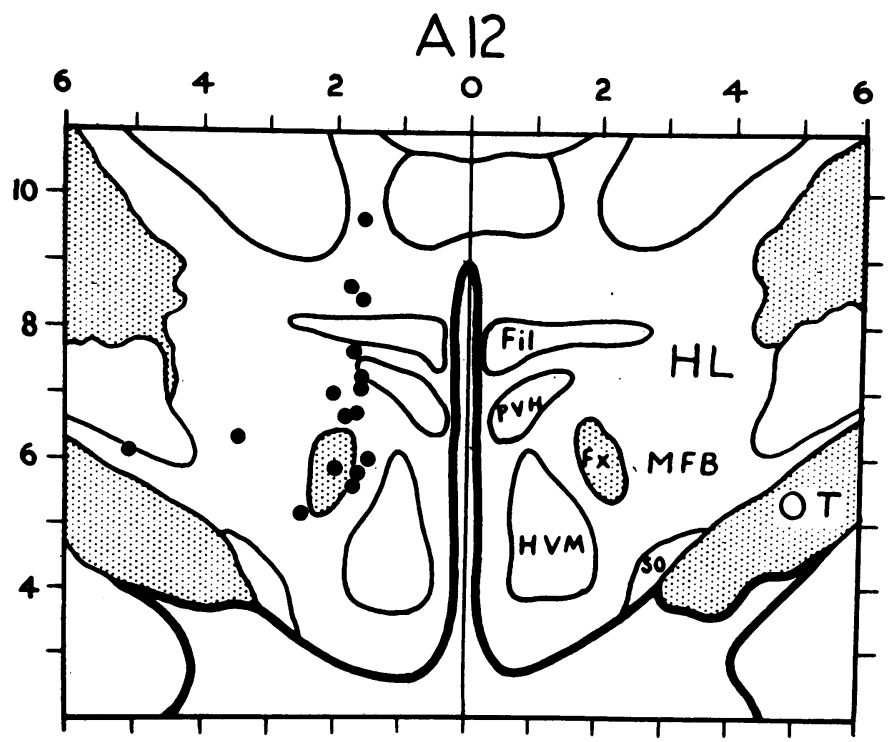

FIG. 2.- Map of frontal plane A 12 showing points from which stimulation produced indepen dent falls in intra-ocular pressure.

$\begin{array}{ll}\text { Fil Nucleus filiformis } \\ \text { Fx } & \text { Anterior column of fornix } \\ \text { HL } & \text { Lateral hypothalamic area }\end{array}$

HVM Ventromedial nucleus of hypothalamus

MFB Medial forebrain bundle

OT Optic tract

PVH Paraventricular nucleus of hypothalamus

SO Supra-optic nucleus

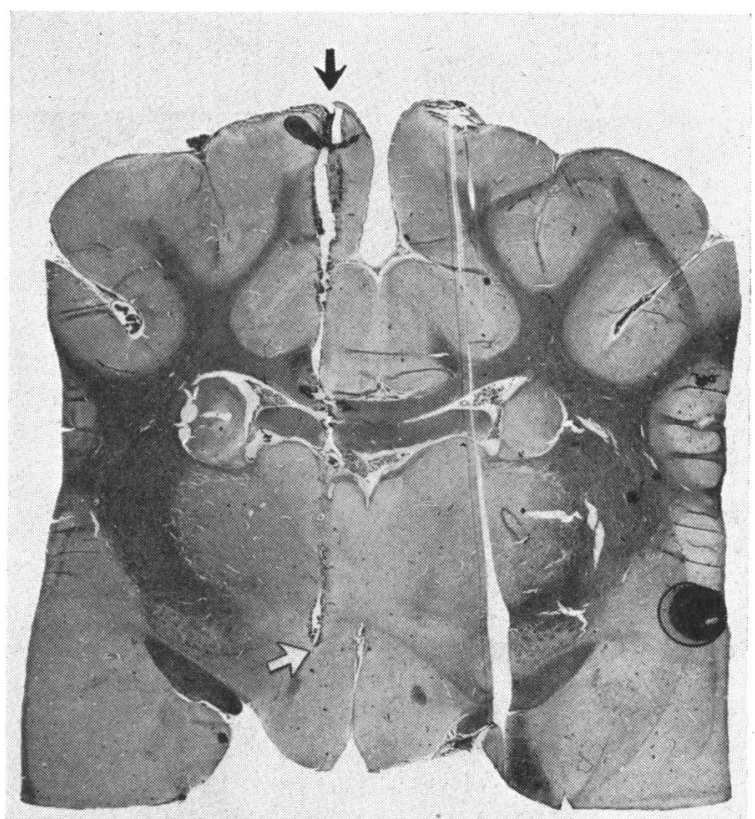

Fig. 3.-Photograph of section showing position of tip of electrode in one of the experiments indicated in Fig. 2. Arrows show extent of electrode track. 
It will be noted that most of the points lie 1.5 to $2 \mathrm{~mm}$. from the mid-line extending from the lower part of the anterior column of the fornix upwards towards the thalamus. In planes A10, A11, and A13, all such points were confined to the medial hypothalamus in the neighbourhood of the anterior column of the fornix.

The points giving the response in the contralateral eye had essentially the same distribution as those for the ipsilateral eye but were less numerous.

\section{(C) Effect of Sympathotomy}

Changes in the characteristics of the response following acute sympathotomy on the same side as hypothalamic stimulation are summarized in the Table; one experiment is reproduced in Fig. 4. This shows that in all animals the fall in intra-ocular pressure in the ipsilateral eye was either reduced or converted into a rise after sympathotomy. No such consistent change was found in the contralateral eye. The blood pressure response was not significantly affected by sympathotomy.

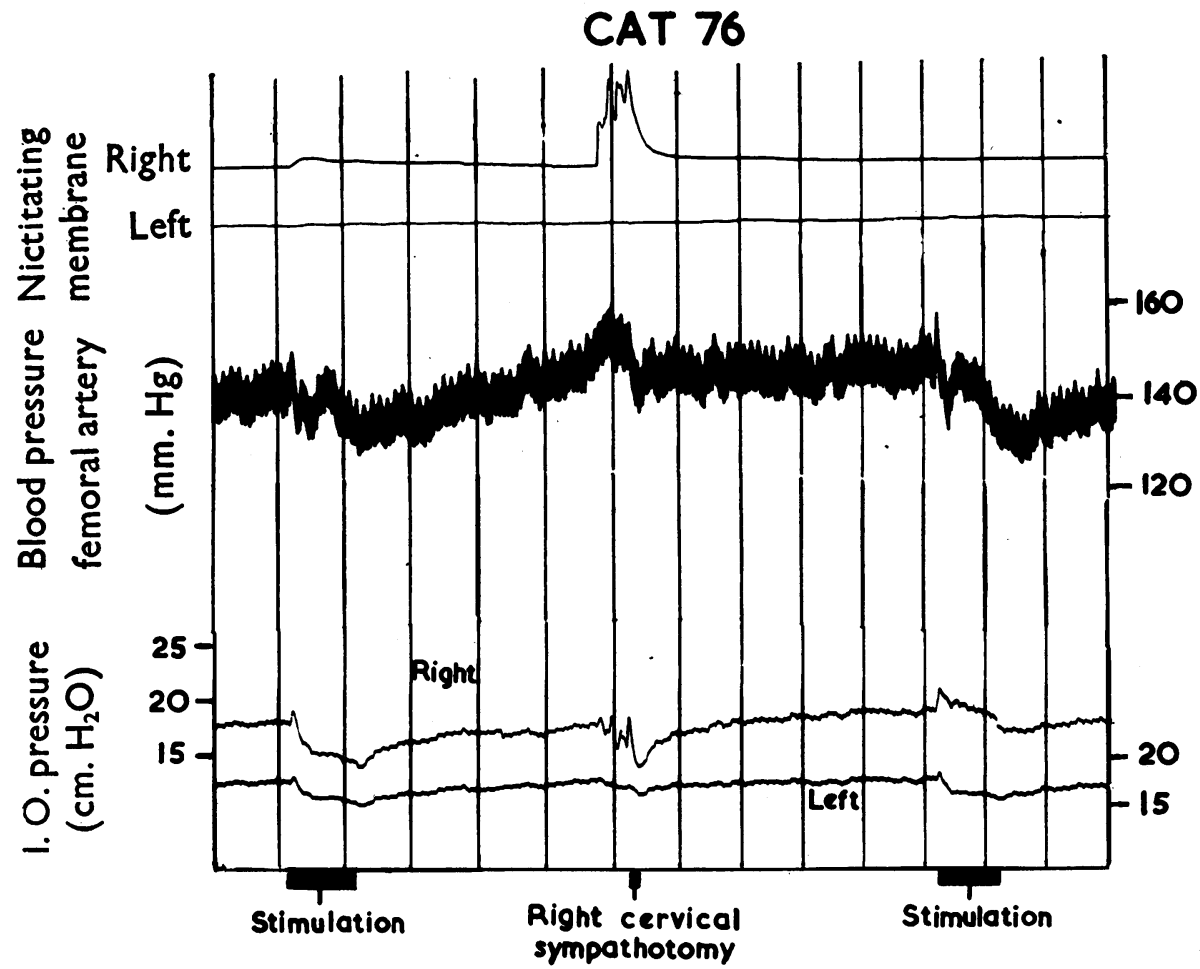

Fig. 4.-Tracing showing effect of sympathotomy on responses obtained from stimulation of a point at $\mathrm{A} 12, \mathrm{R} 1 \cdot 5, \mathrm{H}+6$.

Note that the fall in intra-ocular pressure in the right eye has been converted into a small rise and that the response of the right nictitating membrane has been abolished. The response of the left intra-ocular pressure is unaltered.

Interval between vertical lines $=60 \mathrm{sec}$. 
With regard to the response of the nictitating membrane, it can be seen that four out of the five animals showed an ipsilateral retraction which was abolished by cervical sympathotomy.

In all animals the pupillary responses were modified by ipsilateral sympathotomy; the amount of dilatation in the ipsilateral eye was reduced whilst in the contralateral eye the dilatation was unchanged or increased.

In one animal (H69, see Table) the blood vessels of the ear were observed through a microscope. During stimulation a marked vasoconstriction was noted which did not occur when the stimulation was repeated after sympathotomy.

In three animals the contralateral cervical sympathetic was divided after the effect of ipsilateral sympathotomy had been observed, but these results have not been included in the Table. The fall in intra-ocular pressure in the contralateral eye was always replaced by a rise after contralateral cervical sympathotomy. The responses of the blood pressure were again not significantly changed. The pupillary dilatations were relatively less after cervical sympathotomy, and there were no nictitating membrane responses in the contralateral eye in this series of animals.

TABLE

EFFECT OF CERVICAL SYMPATHOTOMY ON AN OCULAR RESPONSE TO HYPOTHALAMIC STIMULATION

\begin{tabular}{|c|c|c|c|c|c|c|c|c|}
\hline \multirow{2}{*}{$\begin{array}{l}\text { Cat } \\
\text { No. }\end{array}$} & \multirow{2}{*}{$\begin{array}{l}\text { Sympa- } \\
\text { thotomy }\end{array}$} & \multicolumn{2}{|c|}{$\begin{array}{l}\text { Change in Intra- } \\
\text { ocular Pressure } \\
\text { (cm. saline) }\end{array}$} & \multirow{2}{*}{$\begin{array}{c}\text { Change in } \\
\text { Blood } \\
\text { Pressure } \\
(\mathrm{mm} . \mathrm{Hg})\end{array}$} & \multicolumn{2}{|c|}{$\begin{array}{l}\text { Pupillary } \\
\text { Dilatation } \\
(\mathrm{mm} .)\end{array}$} & \multicolumn{2}{|c|}{$\begin{array}{l}\text { Retraction of } \\
\text { Nictitating } \\
\text { Membrane }\end{array}$} \\
\hline & & $\begin{array}{l}\text { Ipsi- } \\
\text { lateral }\end{array}$ & $\begin{array}{l}\text { Contra- } \\
\text { lateral }\end{array}$ & & $\begin{array}{c}\text { Ipsi- } \\
\text { lateral }\end{array}$ & $\begin{array}{l}\text { Contra- } \\
\text { lateral }\end{array}$ & $\begin{array}{c}\text { Ipsi- } \\
\text { lateral }\end{array}$ & $\begin{array}{l}\text { Contra- } \\
\text { lateral }\end{array}$ \\
\hline \multirow[t]{2}{*}{ H67 } & Before & $6 \downarrow$ & $5 \cdot 5 \downarrow$ & $20 \downarrow$ & $6 \cdot 5$ & $5 \cdot 5$ & + & 0 \\
\hline & After & $2 \downarrow$ & $4 \cdot 5 \downarrow$ & $20 \downarrow$ & $4 \cdot 5$ & $6 \cdot 5$ & 0 & 0 \\
\hline \multirow[t]{2}{*}{ H68 } & Before & $1.5 \downarrow$ & $2 \downarrow$ & $13 \uparrow$ & 10 & 9 & 0 & 0 \\
\hline & After & $0.5 \uparrow$ & $2 \downarrow$ & $16 \uparrow$ & 9 & 10 & 0 & 0 \\
\hline \multirow[t]{2}{*}{ H69 } & Before & $2 \cdot 5 \downarrow$ & $2 \downarrow$ & $5 \downarrow$ & 6 & 6 & + & 0 \\
\hline & After & $1.0 \uparrow$ & $1 \downarrow$ & 0 & 2 & 6 & 0 & 0 \\
\hline \multirow[t]{2}{*}{ H73 } & Before & $<1 \downarrow$ & $3 \uparrow$ & $50 \uparrow$ & 9 & 6 & + & 0 \\
\hline & After & $6 \uparrow$ & $6 \uparrow$ & $63 \uparrow$ & 8 & 8 & 0 & 0 \\
\hline \multirow[t]{2}{*}{ H76 } & Before & $3 \downarrow$ & $1.5 \downarrow$ & $7 \downarrow$ & 5 & 5 & + & 0 \\
\hline & After & $2 \uparrow$ & $1.5 \downarrow$ & $5 \downarrow$ & 4 & 6 & 0 & 0 \\
\hline
\end{tabular}

$\uparrow=$ rise $\downarrow=$ fall 


\section{Discussion}

The foregoing results corroborate our previous observation that stimulation near the anterior column of the fornix frequently gives rise to a fall in intra-ocular pressure without a corresponding fall in blood pressure which, together with pupillary dilatation and retraction of the nictitating membrane, constituted an easily recognizable response-pattern. On the basis of the additional results presented here, we have widened our conception of this response-pattern and whilst regarding the fall in intra-ocular pressure as the essential feature, have recognized that the other factors (viz. blood pressure, nictitating membrane, and pupillary dilatation) may show considerable variation. For example, in Fig. $1(b)$, the fall in intra-ocular pressure is accompanied by a fall in systemic blood pressure. We consider that this is a variant of the response already described, since the fall in intra-ocular pressure is too great, in our experience, to be attributed solely to the reduction of blood pressure, and the fact that a diminished fall in intra-ocular pressure occurs after sympathotomy with the same depression of blood pressure, supports this view (see H67 in Table).

The characteristic response-pattern was modified by sympathotomy in all five animals, as can be seen from the Table. In general, the fall in intraocular pressure in the ipsilateral eye was reduced or abolished, there was a relative diminution of the pupillary dilatation, and retraction of the nictitating membrane was eliminated. These changes in the response-pattern must be interpreted either as results of sympathotomy or as progressive alterations in the response as a consequence of repeated stimulation. The latter explanation must be rejected for three reasons:

(1) Repeated stimulation did not consistently yield weaker responses of the intra-ocular pressure, pupils, or nictitating membrane.

(2) In two animals (H68 and H76 in Table) the fall in pressure in the contralateral eye was not decreased after ipsilateral sympathotomy despite reversal of the ipsilateral response of the intra-ocular pressure.

(3) There was no diminution in the pupillary response in the contralateral eye, and in three animals there was actually an increase.

The modification of the response must therefore be the result of sympathotomy and the conclusion to be drawn is that the reduction of intra-ocular pressure, the retraction of the nictitating membrane, and part of the pupillary dilatation, which are produced by electrical stimulation in the region of the fornix, must be mediated wholly or in part by way of the ipsilateral cervical sympathetic nerve. Also, since the similar responses of the intraocular pressure and pupil on the contralateral side were modified by sympathotomy on that side, it follows that each (unilateral) centre exercises some bilateral control.

In the introduction we mentioned the possibility that the response of the intra-ocular pressure to stimulation in this area of the hypothalamus results 
from a constriction of the ocular blood vessels mediated by the cervical sympathetic nerve. It is true that the actual changes in intra-ocular pressure provide only indirect evidence of vasoconstriction, but its occurrence is strongly suggested by the observation of an associated vasoconstriction in the ear. That this reaction may not be confined to the eye is to be expected (see Gloster and Greaves, 1956, 1957).

The effect of cervical sympathotomy upon ocular responses to diencephalic stimulation has also been examined by von Sallmann, Macri, Wanko, and Grimes (1956), who reported that retraction of the nictitating membrane was abolished by sympathotomy, whereas pupillary dilatation was unaffected. Their findings with regard to the response of the intra-ocular pressure are not comparable with ours, since they stimulated a region which produced simultaneous rises of both blood pressure and intra-ocular pressure, neither of these being modified by sympathotomy. With regard to pupillary responses, Weinstein and Bender (1941) showed that the dilatation resulting from stimulation of the ventral hypothalamus of the cat was reduced by cervical sympathotomy, thus indicating that the response was mediated in part by this nerve. Ranson and Magoun (1933) drew attention to the fact that, although pupillary dilatation could be obtained by stimulation in many parts of the hypothalamus, one of the main regions yielding this response was situated around the fornix. Hess (1954) also reported maximal pupillary dilatation on stimulation of the socalled nucleus perifornicalis, an ill-defined area which has been described by Rioch (1929) and by Ingram, Hannett, and Ranson (1932). The area from which we obtained the characteristic response-pattern of a fall in intra-ocular pressure, pupillary dilatation, and retraction of the nictitating membrane appears to conform anatomically with the region described by these workers, and we regard our results as an extension of previous findings which have been limited to observations on the pupils. 'Although our results establish that stimulation in this area of the hypothalamus activates the sympathetic nerve supply to the eye, it is clear that the occurrence of simultaneous changes in the blood vessels of the ear and in the systemic blood pressure show that further evidence is necessary in order to determine whether any part of this area is associated exclusively with the eye.

\section{Summary}

(1) Stimulation in the region of the anterior column of the fornix of the cat produces a typical response characterized by:

(a) a bilateral fall in intra-ocular pressure;

(b) pupillary dilatation;

(c) occasionally retraction of the nictitating membrane;

(d) usually a rise of systemic blood pressure. 
(2) This response is modified by cervical sympathotomy as follows:

(a) the fall in intra-ocular pressure is abolished;

(b) the pupillary dilatation is reduced;

(c) retraction of the nictitating membrane is abolished;

(d) the blood-pressure response is not significantly affected.

(3) This indicates that the response is mediated by way of the cervical sympathetic nerve, and that, as this response is bilateral, stimulation on one side of the hypothalamus results in a discharge in the cervical sympathetic nerve trunks on both sides.

(4) The response is not confined to the eye since simultaneous constriction of the vessels of the ear has been observed.

We should like to thank Sir Stewart Duke-Elder for his continued help and advice; also the Alexander Pigott Wernher Research Trust for a grant covering the expenses of this study.

\section{REFERENCES}

Gloster, J., and Greaves, D. P. (1956). Proc. roy. Soc. Med., 49, 675.

-, (1957). Brit. J. Ophthal., 41, 517.

Greaves, D. P., and Perkins, E. S. (1952). Ibid., 36, 258.

HEss, W. R. (1954). "Diencephalon: Autonomic and Extrapyramidal Functions". Grune and Stratton, New York.

Ingram, W. R., Hannett, F. I , and Ranson, S. W. (1932). J. comp. Neurol., 55, 333.

Ranson, S. W., and Magoun, H. W. (1933). Arch. Neurol. Psychiat. (Chicago), 29, 1179.

RIOCH, D. MCKeNZIE (1929). J. comp. Neurol., 49, 1.

von SarlmanN, L., and Lowenstern, O. (1955). Amer. J. Ophthal., 39, April, Pt. 2, p. 11. -, MACRI, F. J., WANKo, T., and GrIMES, P. A. (1956). Ibid., 42, April, Pt. 2, p. 130. Weinstein, E. A., AND BENDER, M. B. (1941). J. Neurophysiol., 4, 44. 